\title{
A RISK ANALYSIS OF STEVEDORING OPERATIONS IN SEAPORT CONTAINER TERMINALS
}

\author{
Kuo-Chung Shang \\ Department of Transportation and Navigation Science, National Taiwan Ocean University, Keelung City, Taiwan, R.O.C \\ Wen-Jui Tseng \\ Department of Shipping and Transportation Management, National Kaoshiung Marine University, Kaohsiung City, \\ Taiwan, R.O.C, jui@mail.nkmu.edu.tw
}

Follow this and additional works at: https://jmstt.ntou.edu.tw/journal

Part of the Transportation Engineering Commons

\section{Recommended Citation}

Shang, Kuo-Chung and Tseng, Wen-Jui (2010) "A RISK ANALYSIS OF STEVEDORING OPERATIONS IN SEAPORT CONTAINER TERMINALS," Journal of Marine Science and Technology. Vol. 18: Iss. 2, Article 6.

DOI: $10.51400 / 2709-6998.2319$

Available at: https://jmstt.ntou.edu.tw/journal/vol18/iss2/6

This Research Article is brought to you for free and open access by Journal of Marine Science and Technology. It has been accepted for inclusion in Journal of Marine Science and Technology by an authorized editor of Journal of Marine Science and Technology. 


\section{A RISK ANALYSIS OF STEVEDORING OPERATIONS IN SEAPORT CONTAINER}

TERMINALS

Acknowledgements

This research was sponsored by the National Taiwan Ocean University, under NTOU-RD972-01-03-35-01. 


\title{
A RISK ANALYSIS OF STEVEDORING OPERATIONS IN SEAPORT CONTAINER TERMINALS
}

\author{
Kuo-Chung Shang* and Wen-Jui Tseng**
}

Key words: container terminals, stevedoring operations, risk management.

\begin{abstract}
This research is a study of container terminals in Kaohsiung Harbor and investigates risk management in the loading and unloading of container terminals. The study shows that the top three factors associated with severity of accident risk are: "Moving the crane without raising the lifting arm of the gantry crane, resulting in damage to the pilot's compartment," "Transferring containers direct to the trailers," and, "As a result of climatic factors (typhoons), the facility takes no action to prevent collisions." The top three factors associated with frequency of accident risk are, "Ships go by and waves cause a declined-body, raised prow or changed slipped cable," "An overweight container in unbalanced loading causes impact in moving containers," and "Parking trailers do not keep a distance from gantry crane." Finally, through the carrying out the department of risk management to draft out the risk strategies. Under the rational cost could help the terminal operator reduce the effect of container terminals which may be caused by the uncertainty of accident risks to ensure security of operations.
\end{abstract}

\section{INTRODUCTION}

Amid the worldwide trend for large vessels, the efficient operation of container terminals plays an important role nowadays. It has become a significant issue for container terminal operators to systematize the management of risk in loading and unloading operations and maximize the possibility of controlling accident risk effectively (Shang and Lu [12]; Lu and Shang [10]). In recent years, with stepped-up development of container transportation and flourishing trade, con-

Paper submitted 05/14/08; revised 04/01/09; accepted 05/12/09. Author for correspondence: Wen-Jui Tseng (e-mail: jui@mail.nkmu.edu.tw).

*Department of Transportation and Navigation Science, National Taiwan Ocean University, Keelung City, Taiwan, R.O.C.

**Department of Shipping and Transportation Management, National Kaoshiung Marine University, Kaohsiung City, Taiwan, R.O.C. tainer terminals have started to play a vital role in the whole process of logistics and supply chain management. Container terminal operators should therefore establish a complete set of risk management projects in container loading and unloading operations.

For terminal operators, container loading and unloading operations provide the most important link in the supply chain process. In recent years, competition between liner shipping companies has become extremely intense; competition at sea (the increase in navigational technology, faster ships and the trend for increasing size) has expanded to competition on land. Terminal operation is a highly capital-intensive industry, and it is not easy to make profits amid the keen competition. Container terminal operations cannot afford damage caused by unexpected risks. Once an accident occurs during loading and unloading operations, damage may well be inflicted not only on property but also to human life and so forth. The operating cost and the invisible impact on goodwill are harmful to container terminal operators. The execution of risk management in harbors could help to reduce the damage and effectively control container terminal operators' visible and invisible costs. For those companies, the most important matter is to face up to the tough operating environment in this era of micro-profit.

Lu et al. [11] have indicated that, at present, among container terminal operators which suffer container loading and unloading accidents, risk management strategy depends on insurance. Also, monitoring mechanisms have not been fully established. The focus of the research is the risk management of container terminals in loading and unloading, in the light of the various factors involved in risk identification and assessment. The following are the purposes of this study. First, to provide assistance to container terminal operators in risk identification as regards loading and unloading at container terminals, and gain a better understanding of the impact of the risks. Second, to reduce the frequency and severity of loading and unloading accident risk at container terminals and ensure the outcome is reasonable and acceptable to terminal operators. This research discusses risk management in the marshalling yard in Kaohsiung Harbor only. The loading and unloading of vessels, such as tramp carriers and fishing vessels, are not discussed by this study. 


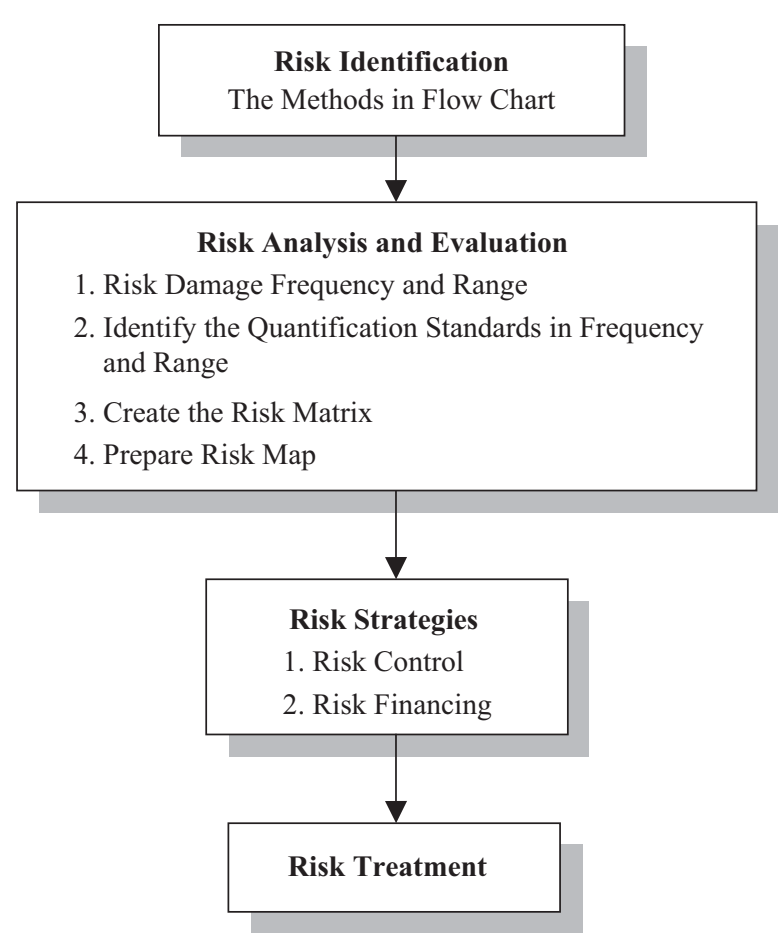

Fig. 1. Analyzed steps of risk evaluation.

The research is based on the four steps of the risk management procedures, which are risk identification, risk analysis and measurement, risk control, and treatment. First of all, to conduct risk identification, we visited and interviewed professionals. Then, we analyzed and measured individual risk factors in damage frequency and severity by using a five-point Likert-type scale in questionnaires. Secondly, we conducted risk analysis and measurement, given the frequency and the severity of the accident, and analyzed the risk causes. Thirdly, we conducted risk control to reduce the frequency of damage and minimize the damage range. Finally, we conducted risk treatment, which is aimed at the risk strategies.

The framework of the remainder of this study is as follows: the second part is the literature review, which reviews the definition of risk management. The third part is an analysis of loading and unloading operations in international container terminals. The fourth part provides a framework for risk management strategies in container terminals at harbors. The fifth and last part is the conclusion and suggestions. Figure 1 shows a flow chart for this study.

\section{LITERATURE REVIEW}

\section{The Definition of Risk Management}

The definitions and interpretations of the term, "risk management," are many and varied (British Bankers' Association [1]; Eloff et al. [3]; Sung [15]; Cheng [2]). The British Bankers' Association [1] considers it to incorporate two major perspectives, "conformance," and "performance." "Conformance" means lowering the damage and threats, and controlling the procedures whereby enterprises reach consistency and stability. "Performance" stresses the growing opportunities and rewards of risk-chasing.

Eloff et al. [3], however, regard risk management as a continuous cycle, usually starting with risk identity, followed by risk analysis, risk evaluation, risk resolution and so forth. Head and Hom [5] explain risk management according to management perspectives and policy decision perspectives. From the management perspectives, risk management emphasizes decreasing the deleterious effects of accidental damage on enterprises; through planning, organization, leadership and control of the processes involved in the enterprise's activities, it helps to reduce these deleterious effects at reasonable cost.

Sung [15] argues that risk management integrates limited resources to lower the deleterious effects. The definition of "economic individuals" includes individual persons, families, enterprises, government institutions, and nations. Also, he stresses that risk management is the combination of what used to be known as "safety management" and "insurance management."

Risk management's main purpose is to develop systems for controlling risk. In fact, enterprises should establish a set of efficient strategies in risk management to achieve the effective protections and control in advance of the risk, reduce the probability of the risk, and avoid damage from the risk. Enterprises should also establish strategies to deal with damage when it does occur; how to bring the business back on track promptly, and limit the costs of the damage are important matters to consider.

Cheng [2] considers that businesses should select methods of risk management suitable for controlling and coping with the various potential net loss risks, with the aim of achieving the lowest risk cost and ensuring safety of business operations. That is to say that business should measure the likely damage frequency and severity, and take advance preventive measures, emphasizing the risk in financial management terms, for the business to prosper and flourish.

\section{Literature on Risk Management}

According to the investigation and analysis by Shiu et al. [14], in accidents occurring during the procedures of supply chain management, those occurring in terminal warehouses and container operation areas account for about twenty-five percent of the total. Most of the accidents are caused by human negligence, indicating that security in harbor management operations should be emphasized and improved. Security in loading and unloading areas also impacts operations, requires ships to dock at harbors, and influences the container terminal operator's costs and service quality. Risk management of container terminals at harbors is therefore very important.

Shiu et al. [13] analyzed transportation risk factors at sea from the viewpoint of the owner of goods, by collecting data 
about events in recent years involving damaged shipping cargos. They evaluated such data as insurance, indemnifications, and categories of goods to assess the accident frequency and severity in relation to different categories of goods, and probed into the causes. The top three damage causes are: (i) Humidity, pollution, rust, and decay. (ii) Inland transportation accidents. (iii) Container terminal operation accidents. The research mainly involved collecting and analyzing data provided by insurance companies in 1999 and 2000. The results showed that accident risk rates in frontline and factory operations at container terminals, and the risk management of loading and unloading tasks are the key areas on which container terminal operators need to place much greater emphasis.

$\mathrm{Li}$ [8] gives the view of the terminal manager at Kaohsiung Harbor Bureau, who claims that the storehouse operations involve many dangerous factors in loading and unloading, shipping, and stock operations. It truly needs to establish "High-Risk Management Strategies." Additionally, Fang [4] claims that accidents of sorts which have occurred in various harbors around the world will not improve as a result of scientific and technological advances; he says that, despite continuous improvements in the technical efficiency of operations and the importance of the harbor management institutions in security, human negligence cannot be eliminated. This study, therefore, takes a terminal operator in Kaohsiung Harbor as its subject, and explores the risk factors involved in container terminal (frontline) operations. It provides suggestions on risk concepts and strategies for the current business operators, and advises that emphasis be placed on risk management to ensure security in loading and unloading operations.

\section{THE CURRENT OPERATION OF CONTAINER TERMINALS IN KAOHSIUNG HARBOR}

There are five terminal centers in Kaohsiung Harbor, which provide speedy and accurate port industry services and the container loading and unloading quantity of the whole harbor can reach ten million TEU annually. Kaohsiung Harbor adopts the container terminal system as the professional docks system, leasing to container terminal operators under contract tenancy agreements. The container terminal operator lessees invest in their own equipment, design and management in the docks, including loading and unloading machines, shipping allocation and container appointed stock areas, and so on.

Under a dedicated terminal system, the container terminal operator invests in the equipment and machines in the rental docks. This study is based on collected data on risks involved in current container terminal loading and unloading operations. Using as its subjects three container terminal operators (terminal operators A, B and C) in Kaohsiung Harbor as case studies, it evaluates and assesses the range and frequency of accident risks.

\section{Analysis of A's Container Terminals}

The dock that terminal operator A currently leases is the deep water terminal. The boats' drafts reach 14 feet and can provide over 3,500 TEU container vessels to berth at the dock. In the loading and unloading task is responsible for the transferred investigation from terminal operator A to the shipping loading and unloading contractor and shipping cargo industry. In the container conveyance task is commuted by the transportation company.

This container terminal operator's tasking method in Kaohsiung Harbor adopts a variety of trailers. Containers are lifted from onboard by gantry crane and placed on trailers, which convey them to the designated stock areas (Imported Areas), from where they are stocked by the transtainer to assigned areas. Containers that need to be withdrawn are loaded onto the trailers and conveyed to the control center.

In the process of ship loading and unloading, although these equipments are in the fixed operation procedure, ship-side loading and unloading to and from assigned container terminals involves certain operational tasks, a gantry crane, transtainer, and stacker trailers. It, however, may cause the equipment to the damage of containers, employees, and even third party damage, because of the dead space in location or equipment or other artificial factors. Those factors may increase the risk at the site of operation.

\section{Analysis of B's Container Terminals}

Terminal operator B currently leases two container terminals in Kaohsiung Harbor and carried out a dredging plan in these terminals' channels in 2005 to meet operating demand. The terminal length is 520 meters. The boats' drafts reach 14.5 meters and the total area of the terminal is about 350,000 square meters. At the present time, there are eight straddle carriers and eight rail transtainers in the container terminals, and at the ship-side there are five gantry cranes. The steady operation quantity in terminal loading and unloading is about 900,000 TEU every year.

The import operation process involves unloading with the gantry crane and placing directly ship-side, then transporting with the straddle carrier to assigned stock areas. If the operation is transtainer then moved to the container terminals with transtainer. If the operation is straddle carrier then moved to the container terminals straddle carrier. In the export procedure, the containers are placed on the loading conveyor belt by the transtainer, where they await conveyance by straddle carrier to the loading operation ship-side. If the operation is straddle carrier then conveyance ship-side is direct. Because of the complexity of the operating equipment, the duty operators may not easily overlook aspects of the operation and it is a highly dangerous process.

\section{Analysis of C's Container Terminals}

Terminal operator $\mathrm{C}$ currently leases four container terminals in Kaohsiung Harbor, and these are located at different 
container centers. Because they are not next to each other. There is a specific plan, however, for loading and unloading operating procedures as well as the moveable planning of the entire container terminals and docks for effective control of non-operators' passing in loading and unloading tasks. Shipping loading and unloading operations are managed by contractors. The conveyance of containers is outsourced to a traffic transportation company.

This terminal operator adopts a method involving a combination of trailers in loading and unloading operations. The containers are lifted from onboard by gantry crane, and loaded onto the trailers. After being moved to assigned stock areas (Imported Areas), they are stored in designated areas by the transtainer. Containers that need to be withdrawn are moved up to trailers to the control center. Another container terminals of this terminal operator, there is no transtainer on the loading and unloading equipment instead of the fork-lift and stacker movement and (un) load the containers.

In the operating procedure of shipping loading and unloading, although those equipment take routine moveable routes, the operation skilled of loading and unloading operators and improper use of equipment are the important keys of accident risk.

\section{THE RESPONDENTS' PROFILES}

The questionnaire design in this research is interviewed specialists. The interviewed specialists were three executive directors of loading and unloading operations in international docks. The content and language used in the questionnaire were revised by three specialists and two scholars after initial design, to facilitate interviewees' understanding.

In order to increase the response rate, the questionnaire was distributed to directors of three container terminal operators, who were authorized to conduct sampling surveys of loading and unloading operations on the spot and to retrieve the completed questionnaires. The survey period was two weeks, from April $25^{\text {th }}$ to May $8^{\text {th }}, 2007$ and 50 questionnaires were distributed to container terminal operators. Among those that were returned, only 13 questionnaires answered the items of risk frequency and 3 questionnaires left out many items; 16 invalid questionnaires were therefore discarded. Table 1 presents statistics about the retrieved questionnaires. Table 2 shows statistical information concerning the respondents' profiles.

The questionnaire adopted a five-point Likert-type scale to evaluate risks. Estimating risk mostly emphasizes damage frequency and severity. Damage frequency means the average rate of risk accidents and damage severity means the financial cost of the damage of risk accidents. It was because statistics on damage frequency and severity in the industry over the years are inaccurate, that we investigated this through our questionnaire. The research adopted five levels of risk frequency, as shown in Table 3.
Table 1. The response rate of the survey.

\begin{tabular}{ccccr}
\hline & $\begin{array}{c}\text { Allotted } \\
\text { Question- } \\
\text { naires (1) }\end{array}$ & $\begin{array}{c}\text { Returned } \\
\text { Question- } \\
\text { naires (2) }\end{array}$ & $\begin{array}{c}\text { Valid } \\
\text { Question- } \\
\text { naires (3) }\end{array}$ & $\begin{array}{c}\text { Response } \\
\text { Rate } \\
(3) /(1)\end{array}$ \\
\hline A & 50 & 28 & 27 & $54 \%$ \\
B & 50 & 34 & 25 & $50 \%$ \\
C & 50 & 33 & 27 & $54 \%$ \\
Total & 150 & 95 & 79 & $52.67 \%$ \\
Amount & & & & \\
\hline
\end{tabular}

Table 2. The respondents' profiles.

\begin{tabular}{|c|c|c|}
\hline Variables & Respondents & Percentage \\
\hline \multicolumn{3}{|l|}{ Gender } \\
\hline Male & 70 & 88.6 \\
\hline Female & 9 & 11.4 \\
\hline \multicolumn{3}{|l|}{ Age } \\
\hline Under 20 years old & 0 & 0 \\
\hline $21-30$ years old & 8 & 10.1 \\
\hline $31-40$ years old & 30 & 38 \\
\hline $41-50$ years old & 30 & 38 \\
\hline Over 51 years old & 11 & 13.9 \\
\hline \multicolumn{3}{|l|}{ Duration of service in } \\
\hline \multicolumn{3}{|l|}{ loading and unloading } \\
\hline \multirow{2}{*}{\multicolumn{3}{|c|}{$\begin{array}{l}\text { operations (in current } \\
\text { company and others) }\end{array}$}} \\
\hline & & \\
\hline Up to 5 years inclusive & 10 & 12.7 \\
\hline $6-10$ years & 23 & 29.1 \\
\hline $11-15$ years & 19 & 24.1 \\
\hline $16-20$ years & 12 & 15.2 \\
\hline 21 years or over & 15 & 19 \\
\hline \multicolumn{3}{|l|}{$\begin{array}{l}\text { The working experience in } \\
\text { this industry }\end{array}$} \\
\hline Among 5 years & 9 & 11.4 \\
\hline $6-10$ years & 24 & 30.4 \\
\hline $11-15$ years & 14 & 17.7 \\
\hline $16-20$ years & 12 & 15.2 \\
\hline 21 years or over & 20 & 25.3 \\
\hline \multicolumn{3}{|l|}{ Current occupation } \\
\hline Office Workers & 20 & 26.3 \\
\hline Duty Monitors & 29 & 38.2 \\
\hline $\begin{array}{l}\text { Duty loading and } \\
\text { unloading operators }\end{array}$ & 27 & 35.5 \\
\hline
\end{tabular}

Table 3. The measurement standard of risk frequency.

\begin{tabular}{ccl}
\hline Level & Situations & \multicolumn{1}{c}{ Frequency } \\
\hline 1 & Unlikely & Once in Over Three Years \\
2 & Seldom & Once in One to Three Years \\
3 & Passable & Once a Year \\
4 & Sometimes & Once in Half to One Year \\
5 & Regularly & Once in Three Months to Half \\
& & Year \\
\hline
\end{tabular}


Table 4. The measurement standard of risk severity.

\begin{tabular}{|c|c|c|c|}
\hline & Types & Non-operators' Loss & $\begin{array}{c}\text { Operators' } \\
\text { Injured } \\
\end{array}$ \\
\hline Level & Situations & Severity & Severity \\
\hline 1 & Slighter & Under NT\$10,000 Dollars & Abrasion \\
\hline 2 & Slight & NT $\$ 10,000$ to & Flesh \\
\hline & & NT\$50,000 Dollars & Wound \\
\hline 3 & Passable & $\begin{array}{l}\text { NT } \$ 50,000 \text { to } \\
\text { NT } \$ 100,000 \text { Dollars }\end{array}$ & Disabled \\
\hline 4 & Critical & $\begin{array}{l}\text { NT } \$ 100,000 \text { Dollars to } \\
\text { NT\$500,000 Dollars }\end{array}$ & Maim \\
\hline 5 & $\begin{array}{c}\text { More } \\
\text { Critical }\end{array}$ & $\begin{array}{l}\text { Above NT } \$ 500,000 \\
\text { Dollars }\end{array}$ & Death \\
\hline
\end{tabular}

Through the interviews with specialists, it concluded the risks which probably involved in some equipment damage and casualty as shown in Table 4.

\section{RESULTS OF EMPIRICAL ANALYSIS}

\section{Analysis and Statistics}

The risk factors associated with container loading and unloading tasks in the questionnaires took the mean and standard deviation (S.D.) of risk severity and frequency, as shown in Table 5. According to Table 5, item 17, the results of accident risk factor analysis are as follows.

The top three accident risks in terms of severity are, "R10: The gantry crane did not lift the boom to move facilities, and caused damage to the pilot's compartment," "R16: Slipped the containers to the trailers directly," and "R14: Because of climatic factors (typhoons), facilities doesn't take any precautions to prevent collisions." The above are risk factors which can cause extensive damage. Compensation is smaller for accidents involving lower severity of risk factors. The three factors of lowest risk severity are - in inverse order of severity - "R5: Inattention to the loading height of ships and the draft depth," "R4: The switch of hatch covers was not coordinated well with conductors and inappropriate use was made of 40- and 20- foot hangers," and "R2: Inappropriate use of the 40- and 20- foot hangers and the unbalanced overweigh containers which caused the moving containers to collide." The risk range management of the container terminal operations should emphasize control of risk in loading and unloading to reduce damage caused by risk accidents.

The top three accident risks in terms of frequency, however, are "R3: Ships go by and waves cause the declined-body, raised prow or changed slipped cable.", "R2: The overweigh container in unbalance loading causes impact in moving containers," and "R8: Parking trailers do not keep a distance from gantry crane." The first two factors refer to the situation in which the gantry crane collides with the containers, and this happens about once a year, so the container terminal operators should prevent these risk accidents from happening. The three least frequently occurring factors - in inverse order of frequency - are "R17: Non-operators injured in the loading and unloading operations areas," "R14: Because of climatic factors (typhoons), facilities don't take any precaution to prevent collisions," and "R16: Slipped the containers to the trailers directly."

The research involved a case study, in order to compare three container terminal operators in risk frequency and risk severity, using variable analysis (ANOVA) to certify causality and verify every situation under the result of average scores and standard deviation and understand the risk level of loading and unloading operations (Tables 6 and 7). Three items in the analysis of variations in severity of risk between three container terminal operators (Table 6) showed dramatic differences, as follows:

(i) "R4: The switch of hatch covers did not cooperate well with conductors and there was inappropriate use of the 40- and 20-foot hangers." In this item of risk factor, container terminal operator A was significantly greater than container terminal operator B.

(ii) "R7: Because of damage to the hanger of the gantry crane, the container locks fell down into the trailers," which container terminal operator A was significantly greater than container terminal operator $\mathrm{C}$.

(iii) In the items "R9: Negligence of duty operators (Speedy raising or inadequate height of gantry crane)" and "R16: Slipped the containers to the trailers directly," container terminal operator A was significantly greater in damage severity than the other two container terminal operators. container terminal operator A was higher in risk damage severity, so the company should develop a controlling mechanism in relation to the aspects of collecting information and controlling risk in risk management.

Four items (Table 7) showed variations between the three container terminal operator in risk frequency which was " $\mathrm{R} 1$ : Inadequate height of hangers or slipped tenons while loading and unloading." Frequency of occurrence was significantly greater for container terminal operator A than for container terminal operator B and C. The item, "R2: Inappropriate use of the 40 and 20 feet hangers and the unbalanced overweigh containers which caused the moving containers to collide," recorded significantly greater frequency of occurrence in container terminal operator A than in container terminal operator C. The item, "R3: Ships go by and waves cause the declined body, raised prow or changed slipped cable," recorded significantly greater frequency of occurrence in container terminal operator A than in container terminal operator B and C. The item, "R8: Parking trailers did not keep a distance from the gantry crane," recorded significantly greater frequency of occurrence in container terminal operator A than in container terminal operator C. Container terminal operator A, therefore, should prevent the risk probability more effectively. 
Table 5. Levels of risk severity and frequency in container terminal operations.

\begin{tabular}{|c|c|c|c|c|c|c|c|}
\hline \multirow{2}{*}{ Risk Factors } & \multicolumn{3}{|c|}{ Severity } & \multicolumn{3}{|c|}{ Frequency } & \multirow{2}{*}{ Sum } \\
\hline & Mean & S.D & Rank & Mean & S.D & Rank & \\
\hline $\begin{array}{l}\text { R10. The gantry crane did not lift the boom to move facilities and } \\
\text { caused damage to the pilot's compartment. }\end{array}$ & 4.27 & 1.27 & 1 & 1.58 & 1.25 & 13 & 5.85 \\
\hline R16. Slipped the containers to the trailers directly. & 4.23 & 1.30 & 2 & 1.38 & 0.81 & 17 & 5.61 \\
\hline $\begin{array}{l}\text { R14. Because of climatic factors (typhoons), facilities do not take any } \\
\text { precaution to prevent collisions. }\end{array}$ & 4.21 & 1.35 & 3 & 1.38 & 0.84 & 16 & 5.59 \\
\hline $\begin{array}{l}\text { R7. Because of damage to the hanger of the gantry crane, the container } \\
\text { locks fell down into the trailers. }\end{array}$ & 4.20 & 1.28 & 4 & 1.58 & 0.95 & 14 & 5.78 \\
\hline $\begin{array}{l}\text { R13. The gantry crane did not move away from the head and back of } \\
\text { ships, or the bridge or mast while touching and offshoring. }\end{array}$ & 4.14 & 1.22 & 5 & 1.61 & 0.67 & 12 & 5.75 \\
\hline $\begin{array}{l}\text { R17. Non-operators were injured in the loading and unloading operation } \\
\text { areas. }\end{array}$ & 3.88 & 1.29 & 6 & 1.58 & 0.76 & 15 & 5.46 \\
\hline $\begin{array}{l}\text { R11. The unreturned suspenders on the ships and the gantry crane_col- } \\
\text { lides with the suspenders while loading and unloading. }\end{array}$ & 3.77 & 1.27 & 7 & 1.71 & 0.88 & 11 & 5.48 \\
\hline $\begin{array}{l}\text { R15. The conductors did not attend to the distance between two gantry } \\
\text { cranes (EC) and instructed EC to move. }\end{array}$ & 3.74 & 1.33 & 8 & 1.72 & 1.09 & 10 & 5.46 \\
\hline $\begin{array}{l}\text { R3. Ships go by and waves cause the declined body, raised prow or } \\
\text { changed slipped cable. }\end{array}$ & 3.70 & 1.36 & 9 & 2.86 & 1.45 & 1 & 6.56 \\
\hline $\begin{array}{l}\text { R1. Inadequate height of hangers or slipped tenons while loading and } \\
\text { unloading. }\end{array}$ & 3.53 & 1.24 & 10 & 2.52 & 1.31 & 7 & 6.05 \\
\hline $\begin{array}{l}\text { R9. Negligence of duty operators (Speedy raising or inadequate height } \\
\text { of gantry crane). }\end{array}$ & 3.43 & 1.27 & 11 & 2.59 & 1.22 & 5 & 6.02 \\
\hline $\begin{array}{l}\text { R12. Because of operating negligence, the fences and suspenders or fell } \\
\text { down to cause damage to the decks or halls. }\end{array}$ & 3.42 & 1.20 & 12 & 2.60 & 1.28 & 4 & 6.02 \\
\hline R6. The gantry crane collides with the trailer while moving the crane. & 3.31 & 1.26 & 13 & 2.58 & 1.17 & 6 & 5.89 \\
\hline R8. Parking trailers did not keep a distance from the gantry crane. & 3.12 & 1.22 & 14 & 2.64 & 1.24 & 3 & 5.76 \\
\hline $\begin{array}{l}\text { R2. Inappropriate use of the } 40 \text { and } 20 \text { feet hangers and the unbalanced } \\
\text { overweigh containers which caused the moving containers to col- } \\
\text { lide. }\end{array}$ & 3.09 & 1.23 & 15 & 2.67 & 1.26 & 2 & 5.76 \\
\hline $\begin{array}{l}\text { R4. The switch of hatch covers did not cooperate well with conductors } \\
\text { and there was inappropriate use of the } 40 \text { - and } 20 \text {-foot hangers. }\end{array}$ & 2.96 & 1.33 & 16 & 2.00 & 1.00 & 9 & 4.96 \\
\hline R5. Inattention to the loading height of ships and the actual draft depth. & 2.87 & 1.41 & 17 & 2.21 & 1.26 & 8 & 5.08 \\
\hline
\end{tabular}

Note: Mean is the average scores.; S.D. is the standard deviation.; Sum $=$ the mean of severity + frequency; The mean scores are based on a 5-point Likert scale showed in Tables 3 and 4.

\section{The Risk Evaluation of Loading and Unloading Operations}

The research took the risk level as standard on the damage frequency and severity on the five-point Likert-type scale. Sung [15] identified the standard of "the risk levels" as the sum of the means for both damage frequency and severity levels. In general, the sum of means in damage frequency and severity could build up a risk matrix chart. Meanwhile, we could classify three different risk areas, which are low, medium and high levels; i.e., the evaluation level from two to four points is low, from five to seven is medium, and from eight to ten is high. The frequency and severity of risk to settle on the point of fall (see Fig. 2).

Figure 3 is the risk matrix in the research. According to the analysis of the returned questionnaires, as shown in Table 5, the sum of means in damage frequency and severity is ranged between 4.96 and 6.56. Thus, all of the items in this study will be classified into medium risk level.

The principles of risk management suggest adopting risk prevention methods to reduce the high probability of risk accidents, and adopting risk control strategies to reduce the damage severity for accidents. According to the results of questionnaires, loading and unloading operations are generally at the medium level of risk. The following are suggestions for risk control strategies in container terminal management.

Firstly, the damage frequency at the first level (F1) and damage severity at the fourth level (S4) of risk: The risks at this level are the risk factors R14 and R16. Because this level of risk is one of high damage severity but low damage frequency, the strictest control should be adopted. Apart from this, through insurance, liability for financial losses could perhaps 
Table 6. One-way ANOVA of analysis of variations in severity of risk between the three container terminal operators.

\begin{tabular}{|c|c|c|c|c|c|}
\hline \multirow[t]{2}{*}{ Risk Factors } & \multicolumn{3}{|c|}{ Terminal Operators } & \multicolumn{2}{|c|}{ ANOVA test } \\
\hline & $\begin{array}{c}\text { A } \\
\text { Mean }\end{array}$ & $\begin{array}{c}\text { B } \\
\text { Mean }\end{array}$ & $\begin{array}{c}\text { C } \\
\text { Mean }\end{array}$ & $\begin{array}{c}\mathrm{F} \\
\text { value }\end{array}$ & $\begin{array}{l}\text { Post Hoc } \\
\text { Tests }\end{array}$ \\
\hline R1. Inadequate height of hangers or slipped tenons while loading and unloading. & 3.58 & 3.67 & 3.37 & 0.38 & \\
\hline $\begin{array}{l}\text { R2. Inappropriate use of the } 40 \text { and } 20 \text { feet hangers and the unbalanced overweigh } \\
\text { containers which caused the moving containers to collide. }\end{array}$ & 3.41 & 2.64 & 3.18 & 2.76 & \\
\hline $\begin{array}{l}\text { R3. Ships go by and waves cause the declined body, raised prow or changed slipped } \\
\text { cable. }\end{array}$ & 2.96 & 2.40 & 2.70 & 1.11 & \\
\hline $\begin{array}{l}\text { R4. The switch of hatch covers did not cooperate well with conductors and there was } \\
\text { inappropriate use of the } 40 \text { - and } 20 \text {-foot hangers. }\end{array}$ & 3.52 & 2.40 & 2.92 & $* 5.07$ & $\mathrm{~A}>\mathrm{B}$ \\
\hline R5. Inattention to the loading height of ships and the actual draft depth. & 2.93 & 2.36 & 3.23 & 2.38 & \\
\hline R6. The gantry crane collides with the trailer while moving the crane. & 3.63 & 3.08 & 3.20 & 1.40 & \\
\hline $\begin{array}{l}\text { R7. Because of damage to the hanger of the gantry crane, the container locks fell } \\
\text { down into the trailers. }\end{array}$ & 4.70 & 4.08 & 3.77 & $* 3.96$ & $\mathrm{~A}>\mathrm{C}$ \\
\hline R8. Parking trailers did not keep a distance from the gantry crane. & 3.37 & 3.08 & 2.88 & 1.06 & \\
\hline $\begin{array}{l}\text { R9. Negligence of duty operators (Speedy raising or inadequate height of gantry } \\
\text { crane). }\end{array}$ & 4.07 & 3.20 & 2.96 & $* * 6.37$ & $\mathrm{~A}>\mathrm{B} ; \mathrm{A}>\mathrm{C}$ \\
\hline $\begin{array}{l}\text { R10. The gantry crane did not lift the boom to move facilities and caused damage to } \\
\text { the pilot's compartment }\end{array}$ & 4.63 & 4.17 & 3.96 & 1.95 & \\
\hline $\begin{array}{l}\text { R11. The unreturned suspenders on the ships and the gantry crane_collides with the } \\
\text { suspenders while loading and unloading. }\end{array}$ & 4.22 & 3.36 & 3.65 & 2.12 & \\
\hline $\begin{array}{l}\text { R12. Because of operating negligence, the fences and suspenders or fell down to } \\
\text { cause damage to the decks or halls. }\end{array}$ & 3.74 & 3.24 & 3.25 & 1.50 & \\
\hline $\begin{array}{l}\text { R13. The gantry crane did not move away from the head and back of ships, or the } \\
\text { bridge or mast while touching and offshoring. }\end{array}$ & 4.48 & 4.08 & 3.85 & 1.87 & \\
\hline $\begin{array}{l}\text { R14. Because of climatic factors (typhoons), facilities do not take any precaution to } \\
\text { prevent collisions. }\end{array}$ & 4.41 & 4.38 & 3.85 & 1.43 & \\
\hline $\begin{array}{l}\text { R15. The conductors did not attend to the distance between two gantry cranes (EC) } \\
\text { and instructed EC to move. }\end{array}$ & 3.82 & 3.89 & 3.54 & 0.43 & \\
\hline R16. Slipped the containers to the trailers directly. & 4.89 & 3.91 & 3.81 & $* 6.29$ & $\mathrm{~A}>\mathrm{B} ; \mathrm{A}>\mathrm{C}$ \\
\hline R17. Non-operators were injured in the loading and unloading operation areas. & 4.19 & 3.81 & 3.61 & 1.34 & \\
\hline
\end{tabular}

Note: *represents significance level $\mathrm{p}<0.05$; **epresents significance level $\mathrm{p}<0.01$.

be placed on the insured, and, because the damage frequency is low, a relatively high level of self-responsibility established in the contract of insurance with a simple shift onto the insured of the burden for the greater part of the loss.

Secondly, damage frequency at the second levels (F2) and damage severity at the third level (S3) of risk area: The risks at these levels are R4 and R5. The risk level involves the medium damage severity and lower damage frequency characteristic; feasible risk management strategies should therefore take risk prevention and risk severity control as principles. It is recommended that operators' reaction skills and staff training be enhanced, and that procedures for standard tasks be established.

Thirdly, damage frequency at the second level (F2) and damage severity at the fourth level of risk (S4): The risks at these levels are R7, R10, R11, R13, R15 and R17. The risk is high-intermediate as regards damage severity, and lower as regards damage frequency; also, the major risk factors in this area result in liability for damage (such as damage to vessels and injury to persons) compensation if an accident occurs. Besides improving staff educational training, the system of rewards and penalties should be set up and executed to reduce damage frequency, and container terminals on the scene should be sure to provide insurance covering financial responsibility and personal injury to shift the high-intermediate severity impact of damage; however, because the damage frequency is not high, and after going through effective damage prevention strategies, the financial damage responsibility and the insurance contract of facilities deductible could be raised to reduce the risk cost.

Fourthly, the damage frequency at the third level (F3) and damage severity at the third level (S3) of risk area: the risks in this area are R2, R6, R8, R9, and R12. The risk area is medium damage severity and frequency; so, to reduce the frequency of damage prevention strategies is the primary aim, by such means as improving the reaction skills of operators, the 
Table 7. One-way ANOVA analysis of risk frequency variations among the three container terminal operators.

\begin{tabular}{|c|c|c|c|c|c|}
\hline \multirow[t]{2}{*}{ Risk Factors } & \multicolumn{3}{|c|}{ Terminal Operators } & \multicolumn{2}{|c|}{ ANOVA test } \\
\hline & $\begin{array}{c}\text { A } \\
\text { Mean }\end{array}$ & $\begin{array}{c}\text { B } \\
\text { Mean }\end{array}$ & $\begin{array}{c}\mathrm{C} \\
\text { Mean }\end{array}$ & $\begin{array}{c}\mathrm{F} \\
\text { value }\end{array}$ & $\begin{array}{l}\text { Post Hoc } \\
\text { Tests }\end{array}$ \\
\hline R1. Inadequate height of hangers or slipped tenons while loading and unloading. & 3.41 & 2.40 & 1.74 & $* * 15.1$ & $\mathrm{~A}>\mathrm{B} ; \mathrm{A}>\mathrm{C}$ \\
\hline $\begin{array}{l}\text { R2. Inappropriate use of the } 40 \text { and } 20 \text { feet hangers and the unbalanced over- } \\
\text { weigh containers which caused the moving containers to collide. }\end{array}$ & 3.41 & 2.72 & 1.89 & $* * 12.9$ & $\mathrm{~A}>\mathrm{C} ; \mathrm{B}>\mathrm{C}$ \\
\hline $\begin{array}{l}\text { R3. Ships go by and waves cause the declined body, raised prow or changed } \\
\text { slipped cable. }\end{array}$ & 3.93 & 2.60 & 2.04 & $* * 17.1$ & $\mathrm{~A}>\mathrm{B} ; \mathrm{A}>\mathrm{C}$ \\
\hline $\begin{array}{l}\text { R4. The switch of hatch covers did not cooperate well with conductors and there } \\
\text { was inappropriate use of the } 40 \text { - and } 20 \text {-foot hangers. }\end{array}$ & 2.26 & 2.00 & 1.75 & 1.86 & \\
\hline R5. Inattention to the loading height of ships and the actual draft depth. & 2.85 & 2.12 & 1.62 & 7.53 & \\
\hline R6. The gantry crane collides with the trailer while moving the crane. & 2.96 & 2.72 & 2.04 & 4.87 & \\
\hline $\begin{array}{l}\text { R7. Because of damage to the hanger of the gantry crane, the container locks fell } \\
\text { down into the trailers. }\end{array}$ & 1.70 & 1.56 & 1.46 & 0.43 & \\
\hline R8. Parking trailers did not keep a distance from the gantry crane. & 3.15 & 2.60 & 2.15 & $* 4.92$ & $\mathrm{~A}>\mathrm{C}$ \\
\hline $\begin{array}{l}\text { R9. Negligence of duty operators (Speedy raising or inadequate height of gantry } \\
\text { crane). }\end{array}$ & 3.11 & 2.52 & 2.12 & 2.19 & \\
\hline $\begin{array}{l}\text { R10. The gantry crane did not lift the boom to move facilities and caused damage } \\
\text { to the pilot's compartment. }\end{array}$ & 1.74 & 1.16 & 1.81 & 1.26 & \\
\hline $\begin{array}{l}\text { R11. The unreturned suspenders on the ships and the gantry crane_collides with } \\
\text { the suspenders while loading and unloading. }\end{array}$ & 1.93 & 1.60 & 1.59 & 1.26 & \\
\hline $\begin{array}{l}\text { R12. Because of operating negligence, the fences and suspenders or fell down to } \\
\text { cause damage to the decks or halls. }\end{array}$ & 3.15 & 2.40 & 2.26 & 3.96 & \\
\hline $\begin{array}{l}\text { R13. The gantry crane did not move away from the head and back of ships, or the } \\
\text { bridge or mast while touching and offshoring. }\end{array}$ & 1.93 & 1.32 & 1.56 & 2.73 & \\
\hline $\begin{array}{l}\text { R14. Because of climatic factors (typhoons), facilities do not take any precaution } \\
\text { to prevent collisions. }\end{array}$ & 1.70 & 1.12 & 1.30 & 3.59 & \\
\hline $\begin{array}{l}\text { R15. The conductors did not attend to the distance between two gantry cranes } \\
\text { (EC) and instructed EC to move. }\end{array}$ & 2.11 & 1.48 & 1.56 & 2.80 & \\
\hline R16. Slipped the containers to the trailers directly. & 1.37 & 1.36 & 1.41 & 0.03 & \\
\hline R17. Non-operators were injured in the loading and unloading operation areas. & 1.82 & 1.44 & 1.48 & 1.98 & \\
\hline
\end{tabular}

Note: *represents significance level $\mathrm{p}<0.05$; **represents significance level $\mathrm{p}<0.01$.

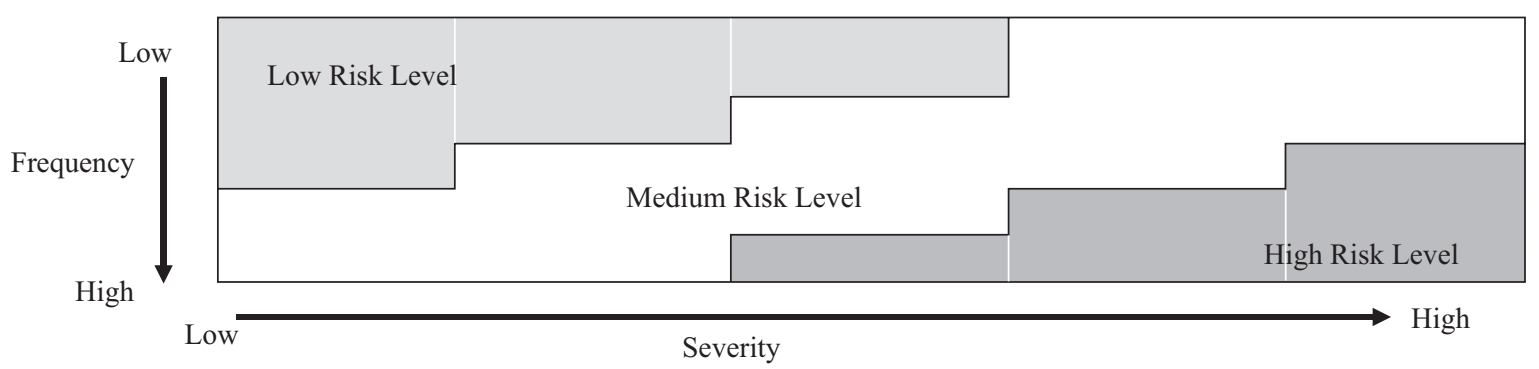

Fig. 2. The risk matrix.

promotion of staff training, the establishment of procedures for standard tasks, the fastening of containers and equipment, the design of a suitable and safe trailing route and enhancement of the trailing routes for truck drivers and so on to prevent accidents from happening.

Fifth, the damage frequency at third level (F3) and damage severity at the fourth level of risk (S4). The risks in this area are R1and R3. Although this risk area is at the medium risk level, its damage severity is at the fourth level, so reducing the severity of damage, mainly through risk control, should be the most impartment strategy. This should include improving the berth working area, promoting staff training, establishing procedures for standard tasks, enhancing the berth crash barrier, and taking out an insurance policy for berth and port facilities. 


\begin{tabular}{|c|c|c|c|c|c|}
\hline Severity $\quad$ Frequency & $\begin{array}{c}1 \\
(\mathrm{~F} 1)\end{array}$ & $\begin{array}{c}2 \\
(\mathrm{~F} 2) \\
\end{array}$ & $\begin{array}{c}3 \\
(\mathrm{~F} 3) \\
\end{array}$ & $\begin{array}{c}4 \\
(\mathrm{~F} 4) \\
\end{array}$ & $\begin{array}{c}5 \\
(\mathrm{~F} 5) \\
\end{array}$ \\
\hline \multicolumn{6}{|l|}{$1(\mathrm{~S} 1)$} \\
\hline \multicolumn{6}{|l|}{$2(\mathrm{~S} 2)$} \\
\hline 3 (S3) & & $\mathrm{R} 4 、 \mathrm{R} 5$ & $\begin{array}{c}\text { R2、R6、R8、 } \\
\text { R9、R12 }\end{array}$ & & \\
\hline 4 (S4) & $\mathrm{R} 14 \cdot \mathrm{R} 16$ & $\begin{array}{c}\mathrm{R} 7 、 \mathrm{R} 10 、 \mathrm{R} 11 、 \mathrm{R} 13 、 \\
\mathrm{R} 15 \cdot \mathrm{R} 17\end{array}$ & $\mathrm{R} 1 、 \mathrm{R} 3$ & & \\
\hline 5 (S5) & & & & & \\
\hline
\end{tabular}

Note: Those codes in risk of matrix are analyzed on the Table 5 levels of risk severity and frequency in container terminal operations.

Fig. 3. The risk matrix in stevedoring operations.

\section{SUGGESTIONS AND CONCLUSION}

This research involved a questionnaire survey and case study. The study was confined to a mere three major container terminal operators, but it found that human factors in loading and unloading operations risks are the major causes of dangerous accidents. The terminal operations should control the probability of risk accidents effectively, especially through staff training. After reviewing the literature, interviewing specialists and designed the questionnaires of container loading and unloading operation risks measurement. Through retrieved questionnaires, it was found that the top three damage severity factors are, "R10: The gantry crane did not lift the boom to move facilities, and caused to damage to the pilot's compartment," "R16: Slipped the containers to the trailers directly," and "R14: Because of climatic factors (typhoons), facilities doesn't take any precautions to prevent collisions." The top three factors associated with frequency of accident risk are "R3: Ships go by and waves cause the declined-body, raised prow or changed slipped cable," "R2: The overweigh container in unbalance loading causes impact in moving containers," and "R8: Parking trailers do not keep a distance from gantry crane."

The accidents of the gantry crane, although the container terminals operators could depend on the past economy to identify risks of loading and unloading tasks, it could probably lack of the concept of risk management. Merely depending on the insurance contract to shift responsibility for the risk, rather than on accurate methods of risk management, probably causes the high frequency of accidents. According to insurants under these contracts, who shoulder responsibility for damage compensation, however, it results in rises in the next year's insurance premium, commensurate with variations in risk frequency and severity in risk areas. Adopted different strategies in damage prevention as well as different risk management methods to make the container terminal dealers control and analyze risks to reach the minimum cost and the maximum profit to win-win conditions. Hopefully, through the discussion about gunnels loading and unloading risk op- eration in the research, and proposed variety of risk management suggestion to container terminal dealer as references:

This study prompts the following suggestions: Firstly container terminal operators could allow risk management departments much greater responsibility and absorb various related department members to compose. They should aim to utilize more professionals, further investigation and overall planning to execute risk management of loading and unloading operations. After a risk manage project has been drafted for loading and unloading, it should be monitored the executive situation constantly and performance assessed. Postaccident review and corrective action must be taken seriously and the initial damage frequency, the severity amount of money and the decision methods to build up the database which provided to related departments as risk management decision methods.

Secondly, in accordance with the risk level of accidents, we classified and set a system of rewards and penalties danger management and we require the container operators to take responsibility and pay attention to risk in order to effectively prevent accidents from happening and ensure that the rate of accidents caused by human factors is reduced.

Thirdly, we take the executive of damage prevention measure thoroughly such as the establishment of container loading and unloading operating procedure, design of routes for trailers, and so on, to reduce the risk accident rate. This could reduce the damage frequency effectively and cut insurance costs. After controlling damage frequency and severity effectively, then we rise up the deductible insurance to shift the insurance merely on the large amount of money in damage risk. The damage within the deductible adopted risk retention strategies so that it could lower the risk management cost and higher up the risk management benefit.

Fourthly, we established the way of insurance contract and shift the greater part of the risk in loading and unloading onto insurance companies. In relation to the insurance contract, we should take particular care about the insurance coverage and exempted items to make sure that the major risk factors are covered as well as if the insurant is covered to avoid the insurance contract is a catchpenny. 
Fifthly, the loading and unloading operators must maintain vigilance over the working environment to reduce the possibility of human negligence. Secondly, the loading and unloading operators should have a better understanding about the standard procedure of loading and unloading tasks and trailer routes to avoid accidents during operations. Thirdly, the crew should conduct maintenance regularly to reduce the potential for risk in loading and unloading equipment.

This study has provided appropriate risk management concepts for container terminal operators to place on the dealers a reasonable burden in terms of risk cost, to make use of risk management methods and effectively prevent accidents involving major damage. Reduced the risk accidents frequency and severity and advised the past concept which misunderstood the insurance was the only tool to manage risks and reached a further the operation security.

Several suggestions have been made for further research. The research investigated only three major container terminal container operators in front-line loading and unloading tasks in Kaohsiung Harbor, further research therefore could expand the scope of the study to international container terminals in Taiwan and the whole loading and unloading procedure. Questionnaires were distributed mainly to the relevant staff on the scene and it could have the differences in cognitions. It is therefore suggested that future research may expand the range of subjects to reduce the drop height of staff's cognitions.

\section{ACKNOWLEDGMENTS}

This research was sponsored by the National Taiwan Ocean University, under NTOU-RD972-01-03-35-01.

\section{REFERENCES}

1. British Bankers' Association, ISDA, Pricewaterhouse Coopers and RMA, "Operational risk: The next frontier," The RMA Journal, Philadelphia, p. 113 (1999).
2. Cheng, T. T., Risk Management-Theory and Practice, 1st Edition, Wu-Nan Book Inc., Taipei (2005).

3. Eloff, J. H. P., Labuschagne L., and Badenhorst, K. P., "A comparative framework for risk analysis method," Computers \& Security, Vol. 12, No. 6, pp. 597-603 (1993).

4. Fang, S. S., "The impact factor of related harbor security," Kaohsiung Harbor, Vol. 13, No. 1, pp. 24-28 (1999).

5. Head, G. L. and Horn, S II., Essentials of the Risk Management Process, Malvern Pa.: Insurance Institute of America (1988).

6. Huang, K. H., The Risk Analysis of Liquefaction (Un) loading Tasks in Bulk in Kaohsiung Harbor, Thesis of Department of Shipping and Transportation Management in National Kaohsiung Marine University, Kaohsiung (2006).

7. Kulp, C. A. \& Hall, J. W., Casualty Insurance, 4th edition, New York: McGraw-Hill (1968).

8. Li, H. C., "Port operation needs management strategies," Kaohsiung Harbor, Vol. 7, No. 6, pp. 2-11 (1993).

9. Ling, Y. B., Kang, Y. M., and Chen, S. S., The Theory and Practical of Insurance, p. 27 (2004).

10. Lu, C. S. and Shang, K. C., "An empirical investigation of safety climate in container terminal operators," Journal of Safety Research. Vol. 36, No. 3, pp. 297-308 (2005).

11. Lu, C. S., Tzeng, W. R., Yang, Y. L., and Shiu, W. H., "The study of container terminal in (Un) loading risk management," Annual Conference Proceedings of the Chinese Institute of Transportation Safety, No. 8, pp. 126-135 (2001).

12. Shang, K. C. and Lu, C. S., "The effects of safety climate on perceptions of safety performance in container terminal operations," Transport Reviews. Vol. 29, No. 1, pp. 1-19 (2009).

13. Shiu, W. H., Lu, C. S., Yang, Y. L., and Tzeng, W, R., "The analysis and strategies of transportation risk factors at the sea," Annual Conference Proceedings of the Chinese Institute of Transportation Safety, pp. 271279 (2000).

14. Shiu, W. W., Lu, C. S., Tseng, W. J., and Yang, Y. L., "The risk management of container terminal operations." Annual Conference Proceedings of the Chinese Institute of Transportation Safety, pp. 126-135 (2000).

15. Sung, M. J., The Modern Risk Management, 5th Edition, Wu-Nan Book Inc., Taipei (2005).

16. Williams, C. A. and Heins, R. M., Risk Management and Insuranc, 6th Edition, McGraw-Hill, New York (1989). 